\title{
Social media medical misinformation: impact on mental health and vaccination decision among university students
}

\author{
Diana Jabbour ${ }^{1} \cdot$ Jad El Masri $^{1} \cdot$ Rashad Nawfal $^{1} \cdot$ Diana Malaeb $^{2} \cdot$ Pascale Salameh $^{2,3,4}$
}

Received: 19 December 2021 / Accepted: 24 January 2022 / Published online: 4 February 2022

(c) The Author(s), under exclusive licence to Royal Academy of Medicine in Ireland 2022

\begin{abstract}
Background The COVID-19 pandemic highlighted the need of social media as a medium for gathering health-related information. Simultaneously, a slew of false information, primarily about COVID-19's origin, dissemination, prevention, treatment, and fatality surfaced, making it difficult to distinguish fake from genuine material. However, the possible effects on mental health and the extent to which this influences our decisions, particularly regarding vaccination, are unknown.

Aim The purpose of this questionnaire-based cross-sectional study was to examine Lebanese University students' perceptions of social media influence during the COVID-19 pandemic, as well as to measure the impact of misinformation on respondents' mental health and vaccination decisions.

Methods In total, 440 students took part and were asked to complete an online survey that included questions on social media trust, the "general health questionnaire index" (GHQ-12), and a scale measuring "attitude towards vaccination".

Results Our data demonstrated a low frequency of mental health disorders among Lebanese University students, which was correlated to frequent social media exposure during the COVID-19 pandemic. These findings suggested that students are more aware of misinformation and had lower rates of despair and anxiety than the general population. Furthermore, Facebook use was associated with worse attitude and behaviour towards vaccination $(p=0.001)$, but a better mental health. Twitter had the inverse effect $(p=0.002)$.

Conclusion It is a necessity to use social media correctly in health-related topics, to push governments and platforms towards making decisions about false and invalidated posts.
\end{abstract}

Keywords COVID-19 pandemic $\cdot$ Medical misinformation $\cdot$ Mental health $\cdot$ Social media $\cdot$ Vaccination

\section{Background}

In December 2019, the novel severe acute respiratory syndrome virus, SARS-COV-2, caused COVID-19 disease and was labelled a worldwide pandemic by the World Health Organization (WHO) [1]. This disease, which was initially

Diana Jabbour

Diana.jabbour@outlook.com

1 Faculty of Medical Sciences, Lebanese University, Hadath Campus, Beirut, Lebanon

2 Faculty of Pharmacy, Lebanese International University, Beirut, Lebanon

3 INSPECT-LB, Institut National de Santé Publique, Épidémiologie Clinique Et Toxicologie-Liban, Beirut, Lebanon

4 Department of Primary Care and Population Health, University of Nicosia Medical School, Nicosia, Cyprus documented in Wuhan, China, exhibits a wide variety of symptoms, including fever, dyspnoea, cough and extrapulmonary signs such as myalgias, neurological abnormalities and gastrointestinal disturbances among others [2]. Human-to-human transmission has been demonstrated even in asymptomatic carriers [3].

Social media, described as "electronic communication in which people share information, thoughts, and ideas", plays an important role in our daily lives by erasing geographic borders, particularly during critical moments like the current COVID-19 outbreak [4, 5]. Social media, as well as other internet websites and platforms, aided immensely in the fight against the new virus by increasing awareness and disseminating instructions on social distancing, face mask use, quarantine and hygiene necessities, all of which helped to slow the virus's spread [6].

Despite the benefits of social media, there is evidence that exaggerated and misinterpreted scientific findings, or even 
fraudulent data, can be produced and publicized, which can have a negative influence on human health. This can indeed pose a significant hazard to public health, making it difficult to distinguish between fact and noise [7].

According to a study conducted in China, $53.8 \%$ of participants described the pandemic's psychological impact as moderate to severe, with accompanying sequelae including post-traumatic stress disorder (PTSD) and other depressive illnesses [8]. A prior study conducted in the USA in 2016 confirmed that false news spreads faster than news from credible sources [9]. This is a major worry since it has the potential to overwhelm people and lead to extreme behaviour. In this context, a man from Africa committed suicide after being diagnosed with COVID-19, and several incidents of medicine overdose have been reported in Nigeria after reading about the benefits of hydroxychloroquine [10]. Meanwhile, a deluge of reports, opinions, rumours and disinformation spread like wildfire across all networks, causing panic and bewilderment among society [11].

Another case of media misrepresentation involves vaccination, where some people expressed their anxiety after reading frightening information and were influenced by antivaccination propaganda, impacting their vaccination decision and creating upstream vaccine hesitation [12].

Nowadays, it is clear that a variety of factors influence people's attitudes regarding vaccination and cause vaccine reluctance. With all of the disinformation it can distribute, social media is at the top of the list, resulting in a decline in vaccination rates as well as a significant impact on people's mental health, particularly in vulnerable communities such as the Lebanese society [13].

As a result, the objective of this study was to assess the influence of social media medical disinformation on the mental health, students' trust in social media as a venue for information gathering and its impact on vaccination attitudes during the COVID-19 pandemic.

\section{Methods}

\section{Study design}

This is a cross-sectional, observational study that was conducted in Lebanon. The target population consisted of Lebanese University students from different faculties. This study was conducted in multiple different locations, rural and urban areas in Lebanon, in order to minimize selection bias as much as possible. The participants were contacted by phone call, recruited via e-mail or social media platforms such as WhatsApp and others and asked for their consent to participate in the study. After fulfilling the consent form, participants completed the questionnaire on Google Forms questionnaire software.
In total, 440 participants pursuing their education at the Lebanese University, aged between 18 and 60, consented to participate in this study and completed the questionnaire. All responses were collected between the 6th and 27th of June 2021.

The questionnaire in English consisted of 4 sections:

- The first part included questions about socio-demographic data.

- The second part was related to the use of different media sources and users' trust in the information media displays [14].

- The third part assessed the mental health of the responders, using GHQ-12 (general health questionnaire) scale [15] which is considered to be a valid and reliable tool to assess psychological distress of our population. Every item is scored with a 4 point Likert scale (from 0 to 3 ) as follows " 0 : Always 1:Usually/often 2: Sometimes/Rarely 3: Never" [16]. Total score ranges from 0 to 36, with higher scores being indicative of worse mental health

- The fourth part inquired about their decision to get vaccinated ("attitude toward vaccination" scale) using a 5-point Likert scale as follows:

$5=$ strongly agree $/ 4=$ agree $/ 3=$ Neutral $/ 2=$ disa gree $/ 1=$ Strongly disagree [17].

\section{Sample size calculation}

According to Lebanese University statistics, there were around 80,874 students registered at the Lebanese University in the academic year 2017-2018 [18].

In order to calculate a representative sample size of the Lebanese University students, the following formula was used:

$N=\frac{\frac{(Z)^{2} * p q}{e^{2}}}{1+\frac{(Z)^{2} * p q}{n e^{2}}}$

with $N$ being the desired sample size.

$n$ represents the total number of Lebanese University students, 80,874 in total.

$Z$ is for the confidence interval considered $95 \%$ in this case and which corresponds to a value of 1.96 .

$p$ will be estimated to be $50 \%$ to get a larger and more conservative sample size in order to decrease Type II error as much as possible.

$q$ is (1-p).e represents the $p$ value we will consider $e=0.05$.

With these numbers in minds, a minimum of 383 students from the Lebanese University was required in order 
to accurately represent the Lebanese population. Therefore, we recruited 440 participants.

\section{Validation and reliability of the scales}

Face validity was established by having the entire questionnaire along with the translation, reviewed and approved by the authors, who have expertise in epidemiology. The pilot study was performed on 100 participants by sending an online questionnaire over WhatsApp and rechecking on them after the survey was completed to ensure that the questions were clear and well understood. The participants stated that everything was clear and that they had no difficulty completing the questionnaire. After conducting this phase, we obtained a Cronbach's alpha $=0.751$ for the "attitudes towards vaccination" scale and a Cronbach's alpha $=0.824$ for the GHQ-12 indicating that the study questionnaire is reliable.

\section{Inclusion and exclusion criteria}

Inclusion criteria included Lebanese University students currently residing in Lebanon and presently enrolled at the university, from different faculties in order to decrease selection bias as much as possible.

The exclusion criteria included graduates and those who did not consent to participate.

\section{Statistical analysis}

The statistical analysis was carried out using SPSS (Statistical Package for Social Sciences) version 25.

Descriptive statistics were used to represent the study variables. Nominal variables were presented as frequencies and percentages. Continuous variables were presented as mean and standard deviation.

Normality distribution of the scales was checked. Bivariate analysis was conducted to test the correlations between the "Trust in Social Media", "General Health Score GHQ12 " and the "Attitude towards Vaccine".

The usual tests were used in the bivariate analysis namely the chi-square test (Fisher exact test) for comparing percentages, Student's $t$-test and ANOVA (Mann-Whitney test and Kruskal Wallis test in case of non-homogeneous variances) for comparing means between 2 or more groups, respectively.

A multivariable analysis was conducted in order to test the factors affecting the Trust in Social Media in the students' population, the General Health Score and the Attitude Towards Vaccine; multiple regressions and logistic regressions were used.

In all cases, a test was considered statistically significant when the $p$ value was less than 0.05 .

\section{Ethical considerations}

The research proposal was approved by the ethics committees of the Lebanese International University with the corresponding number: 2020RC-043-LIUSOP on the 6th of June 2021. A written informed consent form was also completed by all participants who agreed to participate in the study after they read the questionnaire introduction explaining the anonymity and confidentiality of the data, as well as the right to drop out of the study at any time without retributions or repercussions.

\section{Results}

\section{Univariate analysis}

After rejecting responses that were not eligible, we were left with a total of 440 Lebanese university students from all Lebanese governorates, of whom 23\% were enrolled in health-related careers. Participants were distributed between 117 (40.2\%) males and 263 (59.8\%) females. The average age was $21.24 \pm 3.25$ years, and the majority of participants 67.7\% $(n=298)$ lived in Mount Lebanon (Table 1).

Of the studied population, $322(73.2 \%)$ participants reported using Google most commonly, while only 43 individuals (9.8\%) used Twitter (Table 2). Most participants do not search for medical information on a daily basis (57.7\%).

Mental health was assessed using GHQ-12. Mean score was $16.1 \pm 4.9$ with a minimum of 5 and a maximum of 33. Majority of participants had moderate scores on mental

Table 1 Representation of socio-demographic characteristics in the study population $(N=440)$

\begin{tabular}{llll}
\hline Category & Factor & Frequency & Percent \\
\hline Gender & Male & 177 & 40.2 \\
& Female & 263 & 59.8 \\
Age & Mean (SD) & $21.21(3.25)$ & \\
Living Location & Median [Min-Max] & $21[18-65]$ & \\
& Beirut & 46 & 10.5 \\
& Mount Lebanon & 298 & 67.7 \\
& North/Akkar & 39 & 8.9 \\
& South/Nabatieh & 23 & 5.2 \\
& Bekaa/Baalbeck & 34 & 7.7 \\
Level of education & Freshman & 47 & 10.7 \\
& Second/Third year & 199 & 45.2 \\
& Fourth year and above & 85 & 19.3 \\
& Bachelor/Master & 97 & 22 \\
& PHD/MD & 12 & 2.7 \\
Are you a healthcare & No & 339 & 77 \\
professional? & Yes & 101 & 23 \\
\hline
\end{tabular}


Table 2 Most used media platform to gather health-related information

\begin{tabular}{lcr}
\hline Category & Frequency & Percent \\
\hline $\begin{array}{l}\text { Most commonly used media platform to gather health related } \\
\text { information }\end{array}$ & \\
Facebook & 194 & 19.1 \\
Instagram & 322 & 43.2 \\
Google & 140 & 73.2 \\
TV news & 136 & 31.8 \\
YouTube & 43 & 30.9 \\
Twitter & 254 & 9.8 \\
How frequently do you search for medical information on & media? \\
Not everyday & 96 & 57.7 \\
Once a day & 62 & 21.8 \\
2-5 times a day & 13 & 14.1 \\
5-10 times a day & 15 & 3.0 \\
More than 10 times a day & & 3.4 \\
\hline
\end{tabular}

health scale, with a mild orientation towards good mental health. Very few participants had extremely bad mental health (Fig. 1A) indicating a low prevalence of mental health problems.

Attitude towards COVID-19 vaccination was assessed using an 8-item score following a Likert scale from 1 to 5 . Mean attitude score was $25.54 \pm 5.8$ over 40 with a minimum of 8 and a maximum of 40 . Around half of the participants had a moderate response concerning attitude towards
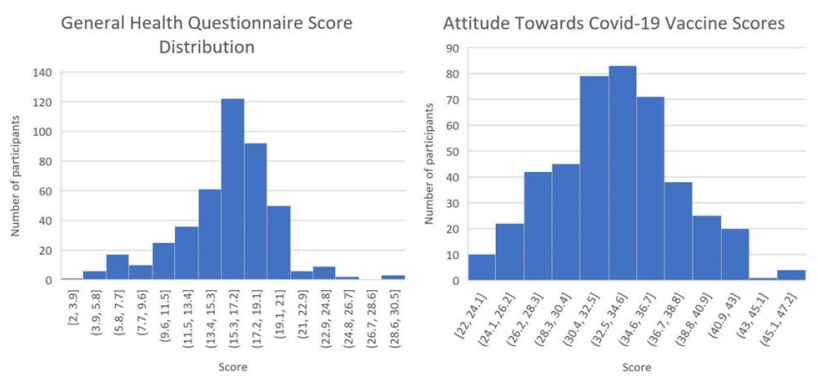

Fig. 1 A Distribution of scores on general health questionnaire (GHQ-12). B Distribution of scores on attitude towards COVID-19 vaccine scale

vaccine, with those having bad attitude somehow equal to those having bad attitude (Fig. 1B).

Most participants stated that they would take the vaccine $n=315(71.6 \%)$. Of those who would get vaccinated, reading about the safety and effectiveness of COVID-19 vaccine was the main argument (37.4\%). And of those who would not take the vaccine $(n=125)$, the main reason was reading that it was not safe nor effective $n=82$ (70.7\%) (Table 3). In addition, $121(27.4 \%)$ of the participants described social media impacted moderately their vaccination decision.

Out of the 440 participants, $393(89.3 \%)$ stated that most social media posts can be trusted; $273(62 \%)$ agreed that most of the time, people sharing social media posts try to be helpful; 293 (66.6\%) agreed that most people are honest by sharing posts online. In addition, 201 (45.7\%) click to

Table 3 Behaviour towards COVID-19 vaccine

\begin{tabular}{|c|c|c|c|}
\hline Category & Factor & Frequency & Percent \\
\hline \multirow[t]{2}{*}{ Would you take COVID-19 vaccine? } & No & 125 & 28.4 \\
\hline & Yes & 315 & 71.6 \\
\hline \multirow{5}{*}{$\begin{array}{l}\text { If yes, which statement popular on media best justifies } \\
\text { your decision regarding vaccination? }\end{array}$} & I read COVID-19 vaccine is safe and effective & 116 & 37.4 \\
\hline & It will protect me from infection with COVID-19 & 75 & 24.2 \\
\hline & A celebrity recommends it & 1 & 0.3 \\
\hline & It reduces complications and hospitalization & 110 & 35.5 \\
\hline & Most people on media said they took it & 8 & 2.6 \\
\hline \multirow{5}{*}{$\begin{array}{l}\text { If no, which statement popular on media best justifies } \\
\text { your decision regarding vaccination? }\end{array}$} & It's not safe/tested enough & 82 & 70.7 \\
\hline & People say it's dangerous, I may get COVID-19 from it & 12 & 10.3 \\
\hline & A celebrity advocate against it & 7 & 6 \\
\hline & It's a marketing, it doesn't work & 6 & 5.2 \\
\hline & It's a microchip to track people and modify their genes & 9 & 7.8 \\
\hline \multirow[t]{5}{*}{ To which level social media affected your choice? } & Not at all & 98 & 22.3 \\
\hline & A little bit & 77 & 17.5 \\
\hline & Moderately & 144 & 32.7 \\
\hline & Somewhat & 103 & 23.4 \\
\hline & Extremely & 18 & 4.1 \\
\hline
\end{tabular}


Table 4 Social media trust and perceived validity of posts

\begin{tabular}{|c|c|c|c|}
\hline Category & Factor & Frequency & Percent \\
\hline \multirow{2}{*}{$\begin{array}{l}\text { Generally speaking, would you say that most social media posts can be trusted or } \\
\text { that you can't be too careful in dealing with them? }\end{array}$} & Most social media posts can be trusted & 47 & 10.7 \\
\hline & Can't be too careful & 393 & 89.3 \\
\hline \multirow{2}{*}{$\begin{array}{l}\text { Would you say that most of the time, people sharing social media posts try to be } \\
\text { helpful, or that they are mostly just looking out for themselves? }\end{array}$} & Try to be helpful & 273 & 62 \\
\hline & Look out for themselves & 167 & 38 \\
\hline \multirow{2}{*}{$\begin{array}{l}\text { Do you think that most people sharing posts online would try to mislead you if } \\
\text { they got the chance or would they try to be honest? }\end{array}$} & Mislead me & 147 & 33.4 \\
\hline & Try to be honest & 293 & 66.6 \\
\hline \multirow[t]{6}{*}{ Which one of these actions would you likely do when you see such post? } & Share the post & 17 & 3.9 \\
\hline & Comment the post & 8 & 1.8 \\
\hline & Like the post & 76 & 17.3 \\
\hline & Dislike the post & 5 & 1.1 \\
\hline & Click to read more & 201 & 45.7 \\
\hline & Ignore the post & 133 & 30.2 \\
\hline \multirow[t]{4}{*}{ What is your perceived validity of the post? } & I believe it & 31 & 7 \\
\hline & I don't believe it & 32 & 7.3 \\
\hline & I am not sure & 335 & 76.1 \\
\hline & I don't care if it is true or not true & 42 & 9.5 \\
\hline
\end{tabular}

read posts, and $335(76.1 \%)$ are not sure of the validity of the posts (Table 4).

\section{Bivariate analysis}

Attitude score was not associated with participants' gender $(p=0.167)$, age (0.906), living area $(p=0.243)$ and educational level $(p=0.084)$. Attitude score was higher in healthcare workers $($ mean $=27.26 \pm 5.25)$ compared to non-healthcare workers $($ mean $=25.03 \pm 5.85)(p=0.001)($ Table 5).
Attitude towards vaccination was higher in participants who do not trust social media $($ mean $=25.71 \pm 5.89)$, when compared to those who trust social media $(p=0.038)$. In addition, attitude towards vaccination was higher in participants who believe that most people sharing posts try to be honest $($ mean $=26.18 \pm 5.02)$, when compared to those who believe that people mislead them $(p=0.008)$. Attitude towards vaccination was higher in participants who do not use Facebook $($ mean $=25.06 \pm 5.66)(p=0.001)$ and those who use Twitter $($ mean $=27.88 \pm 5.71)(p=0.002)$. Attitude
Table 5 Bivariate analysis: socio-demographics and attitude towards vaccine

\begin{tabular}{lllllll}
\hline Category & Factor & Number & Mean (SD) & $\begin{array}{l}\text { 95\% confidence } \\
\text { interval for } \\
\text { mean }\end{array}$ & Min-Max & $p$ value \\
& & & & & \\
\hline \multirow{2}{*}{ Gender } & Male & 177 & $25.88(6.37)$ & $24.94-26.83$ & Aug-40 & $0.167 \mathrm{a}$ \\
& Female & 263 & $25.32(5.36)$ & $24.66-25.97$ & Oct-38 & \\
Age & $\leq 21$ years & 275 & $25.54(5.73)$ & $24.86-26.22$ & Aug-40 & $0.906 \mathrm{a}$ \\
& Location & 165 & $25.55(5.91)$ & $24.64-26.46$ & Dec-37 & \\
& Beirut & 46 & $25.48(5.99)$ & $23.70-27.26$ & $13-37$ & $0.243 \mathrm{~b}$ \\
& Mount Lebanon & 298 & $26.00(5.56)$ & $25.36-26.63$ & Dec-40 & \\
& North/Akkar & 39 & $24.03(6.56)$ & $21.90-26.15$ & Aug-34 & \\
& South/Nabatieh & 23 & $25.26(5.68)$ & $22.80-27.72$ & $13-35$ & \\
Educational Level & Fekaa/Baalbeck & 34 & $23.59(6.23)$ & $21.41-25.76$ & Sep-35 & \\
& Freshman & 47 & $24.34(6.80)$ & $22.34-26.34$ & Aug-36 & $0.084 b$ \\
& Second/Third year & 199 & $25.66(5.06)$ & $24.95-26.37$ & Nov-38 & \\
& Fourth year and above & 85 & $26.94(6.07)$ & $25.63-28.25$ & Dec-37 & \\
& Bachelor/Master & 97 & $24.56(6.14)$ & $23.32-25.80$ & Oct-40 & \\
& PHD/MD & 12 & $26.42(6.58)$ & $22.23-30.60$ & $14-36$ & \\
Healthcare worker & No & 339 & $25.03(5.85)$ & $24.41-25.66$ & Aug-40 & $0.001 \mathrm{a}$ \\
& Yes & 101 & $27.26(5.25)$ & $26.22-28.29$ & $14-37$ & \\
\hline
\end{tabular}

Analysis done using Mann-Whitney U test (a) and Kruskal Wallis (b) 
towards vaccination was not associated to the usage of Instagram $(p=0.375)$, Google $(p=0.413)$, TV news $(p=0.413)$ and YouTube $(p=0.293)$ and the frequency of search for medical information on media (Table 6).

Attitude towards vaccination was higher in participants who were willing to take COVID-19 vaccine $($ mean $=27.69 \pm 4.55)$ compared to those who are not willing to be vaccinated $(p<0.001)$. The will to be vaccinated increased 1.4 times with a $95 \%$ confidence interval (1.310-1.499) with the increasing of the attitude score. Attitude towards vaccination was higher in participants who stated that social media do not affect their choice regarding vaccination $(p<0.001)$. Attitude towards vaccination was not associated with the mental health status $(p=0.333)$ (Table 7).

Among those who would take the vaccine, $16.2 \%$ were Facebook users, while among those who would not, $26.4 \%$ were Facebook users $(p=0.014)$. On the other hand, Twitter users showed the opposite trend as $12 \%$ would take the vaccine, compared to $4 \%$ among non-users $(p=0.01)$ (Table 7) (Fig. 2).

\section{Linear regression and multivariate analysis}

Linear regression showed that a better attitude towards vaccination was positively associated with the use of Facebook $(B=2.003$ [95\% CI 0.946-3.06]; $p<0.001)$.

It was inversely associated with social media trust $(B=-2.1[95 \% \mathrm{CI}-3.457,-0.754] ; p=0.002)$.

Multivariate analysis showed that a better attitude towards vaccination was positively associated with being a healthcare worker $(B=2.176$ [95\% CI 0.953-3.398]; $p<0.001)$, use of Twitter ( $B=2.646$ [95\% CI 0.922-4.37]; $p<0.001)$ and trust of people sharing posts on social media $(B=1.948$ [95\% CI 0.788-3.109]; $p<0.001$ ).

It was inversely associated with Facebook use $(B=-2.251$ [95\% CI $-3.572,-0.929] ; p<0.001)$ and being affected by

Table 6 Bivariate analysis: social media use and attitude towards vaccine

\begin{tabular}{|c|c|c|c|c|c|c|}
\hline Category & Factor & Number & Mean (SD) & $\begin{array}{l}95 \% \text { confidence } \\
\text { interval for } \\
\text { mean }\end{array}$ & Min-Max & $p$ value \\
\hline \multirow{2}{*}{$\begin{array}{l}\text { Generally speaking, would you say that most social } \\
\text { media posts can be trusted or that you can't be too } \\
\text { careful in dealing with them? }\end{array}$} & $\begin{array}{l}\text { Most social media posts } \\
\text { can be trusted }\end{array}$ & 47 & $24.13(4.69)$ & $22.75-25.50$ & Dec-34 & \multirow[t]{2}{*}{$0.038 \mathrm{a}$} \\
\hline & Can't be too careful & 393 & $25.71(5.89)$ & $25.13-26.30$ & Aug-40 & \\
\hline \multirow{2}{*}{$\begin{array}{l}\text { Would you say that most of the time, people sharing } \\
\text { social media posts try to be helpful, or that they are } \\
\text { mostly just looking out for themselves? }\end{array}$} & Try to be helpful & 273 & $26.09(5.19)$ & $25.47-26.71$ & $13-40$ & \multirow[t]{2}{*}{$0.078 \mathrm{a}$} \\
\hline & Look out for themselves & 167 & $24.65(6.58)$ & $23.65-25.66$ & Aug-37 & \\
\hline \multirow{2}{*}{$\begin{array}{l}\text { Do you think that most people sharing posts online } \\
\text { would try to mislead you if they got the chance or } \\
\text { would they try to be honest? }\end{array}$} & Mislead me & 147 & $24.27(6.93)$ & $23.14-25.40$ & Aug-40 & \multirow[t]{2}{*}{$0.008 \mathrm{a}$} \\
\hline & Try to be honest & 293 & $26.18(5.02)$ & $25.60-26.76$ & $13-38$ & \\
\hline \multirow[t]{2}{*}{ Facebook } & No & 356 & $26.05(5.66)$ & $25.46-26.64$ & Sep-40 & \multirow[t]{2}{*}{$0.001 \mathrm{a}$} \\
\hline & Yes & 84 & $23.39(5.87)$ & $22.12-24.67$ & Aug-34 & \\
\hline \multirow[t]{2}{*}{ Instagram } & No & 250 & $25.73(5.95)$ & 24.99-26.47 & Aug-38 & \multirow[t]{2}{*}{$0.375 \mathrm{a}$} \\
\hline & Yes & 190 & $25.30(5.59)$ & $24.50-26.10$ & Sep-40 & \\
\hline \multirow[t]{2}{*}{ Google } & No & 118 & $25.21(5.81)$ & $24.15-26.27$ & Oct-40 & \multirow[t]{2}{*}{$0.413 \mathrm{a}$} \\
\hline & Yes & 322 & $25.66(5.79)$ & $25.03-26.30$ & Aug-38 & \\
\hline \multirow[t]{2}{*}{ TV news } & No & 300 & $25.37(5.93)$ & $24.70-26.05$ & Aug-40 & \multirow[t]{2}{*}{$0.413 \mathrm{a}$} \\
\hline & Yes & 140 & $25.91(5.48)$ & 24.99-26.82 & Dec-38 & \\
\hline \multirow[t]{2}{*}{ YouTube } & No & 304 & $25.75(5.45)$ & $25.13-26.37$ & Oct-40 & \multirow[t]{2}{*}{$0.293 \mathrm{a}$} \\
\hline & Yes & 136 & $25.08(6.49)$ & $23.98-26.18$ & Aug-38 & \\
\hline \multirow[t]{2}{*}{ Twitter } & No & 397 & $25.29(5.71)$ & $24.73-25.85$ & Aug-40 & \multirow[t]{2}{*}{$0.002 \mathrm{a}$} \\
\hline & Yes & 43 & $27.88(6.12)$ & $26.00-29.77$ & Dec-37 & \\
\hline \multirow{5}{*}{$\begin{array}{l}\text { How frequently do you search for medical information } \\
\text { on media? }\end{array}$} & Not everyday & 254 & $25.74(5.69)$ & $25.04-26.44$ & Aug-40 & \multirow[t]{5}{*}{$0.393 b$} \\
\hline & Once a day & 96 & $24.82(6.03)$ & $23.60-26.05$ & Nov-37 & \\
\hline & $2-5$ times a day & 62 & $26.06(6.37)$ & $24.45-27.68$ & Sep-37 & \\
\hline & 5-10 times a day & 13 & $23.85(2.64)$ & $22.25-25.44$ & $19-28$ & \\
\hline & More than 10 times a day & 15 & $26.13(5.19)$ & $23.26-29.01$ & $17-36$ & \\
\hline
\end{tabular}

Analysis done using Mann-Whitney U test (a) and Kruskal Wallis (b) 
Table 7 Bivariate analysis: willingness to vaccination, mental health and attitude towards vaccine

\begin{tabular}{|c|c|c|c|c|c|c|}
\hline Category & Factor & Number & Mean (SD) & $\begin{array}{l}95 \% \text { confidence } \\
\text { interval for mean }\end{array}$ & Min-Max & $p$ value \\
\hline \multirow[t]{2}{*}{ Would you take COVID-19 vaccine? } & No & 125 & $20.14(5.02)$ & $19.25-21.02$ & Aug-34 & \multirow[t]{2}{*}{$<0.001 \mathrm{a}$} \\
\hline & Yes & 315 & $27.69(4.55)$ & $27.18-28.19$ & $14-40$ & \\
\hline \multirow{5}{*}{$\begin{array}{l}\text { To which level social media affected your } \\
\text { choice? }\end{array}$} & Not at all & 98 & $27.62(6.66)$ & $26.29-28.96$ & Oct-40 & \multirow[t]{5}{*}{$<0.001 \mathrm{~b}$} \\
\hline & A little bit & 77 & $25.94(5.86)$ & $24.60-27.27$ & $13-37$ & \\
\hline & Moderately & 144 & $24.58(5.20)$ & $23.72-25.43$ & Nov-35 & \\
\hline & Somewhat & 103 & $24.57(5.24)$ & $23.55-25.60$ & Aug-36 & \\
\hline & Extremely & 18 & $25.83(5.29)$ & $23.20-28.47$ & Dec-36 & \\
\hline Mental health assessment & \multicolumn{5}{|c|}{ Spearman's correlation coefficient $(-0.046)$} & $0.333 \mathrm{c}$ \\
\hline
\end{tabular}

Analysis done using Mann-Whitney U test (a), Kruskal Wallis (b), Spearman's correlation test

social media $(B=-0.79[95 \% \mathrm{CI}-1.234,-0.345] ; p<0.001)$

(Table 8).

\section{Discussion}

To the best of our knowledge, our study is the first to be done in Lebanon during the COVID-19 pandemic to assess the impact of social media platforms on persons' psychological wellbeing and attitudes regarding vaccination. It also emphasizes the importance of media platforms on the health-related decisions of a developing country's young population. The most crucial outcome of our investigation was a clear perception that Facebook users had a negative attitude towards vaccination, as compared to Twitter users, who had a positive overall opinion. Facebook was a fertile, broad arena for anti-vaccine promoters, but Twitter was far more restricted. In terms of psychological wellbeing, Facebook was connected with a better outcome, whereas Twitter was correlated with a worse outcome.

As expected, being involved in a health-related career was associated with improved acceptance and uptake of the COVID-19 vaccine $(p=0.001)$. This was consistent with the findings of other studies conducted in countries such as Italy,

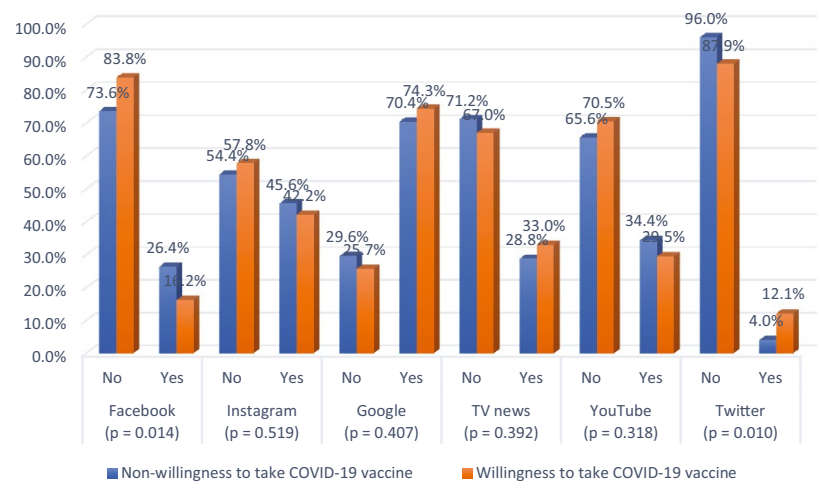

Fig. 2 Willingness to vaccination and social media use
Saudi Arabia and the Democratic Republic of the Congo [19-21]. It is owing to the high degree of knowledge in this sector, the awareness of how crucial vaccination and herd immunity are in mitigating the pandemic [22], as well as how important it is for them to get protected as front-liners in this pandemic, particularly susceptible to infection at their institutions. This could be an effective strategy for engaging people in vaccination because many patients communicate solely with their physicians and rely on their advice when it comes to health-related decisions, as demonstrated in the past with the HPV vaccine, where uptake was highly linked to HCP (health care professionals) recommendations [23].

The usage of Facebook resulted in a significant decrease in belief in the safety and efficacy of COVID-19 vaccinations. This can be explained by the large number of posts and comments by people from non-health-related fields encouraging people to reject vaccination and attempting to promote an anti-vaccination movement, spreading rumours and false claims about the COVID-19 vaccine, denying its efficacy and exaggerating its risks [24]. In this context, a study conducted in the USA found that a higher number of comments expressing negative sentiments about the vaccine resulted in a negative attitude towards its uptake [25]. Furthermore, Facebook was claimed to be a major platform for debates and discussion concerning health-related issues [26] and based on the fact that healthcare providers were not very active on Facebook (Facebook use was around 65\% of Twitter users and 50\% of blog use) [27], and with a lack of professionalism [28], this played a negative role in spreading awareness about the importance of vaccination. This was also true for a number of other vaccines, including polio and influenza vaccines [25, 29]. These findings were consistent with our findings, which showed that Facebook users exhibited negative views and behaviours regarding the COVID-19 vaccine ( $p=0.001$ and $p=0.014$, respectively).

Using Twitter, on the contrary to what was previously stated, significantly improved behaviour and attitude towards vaccination. Twitter is regarded as a critical tool 


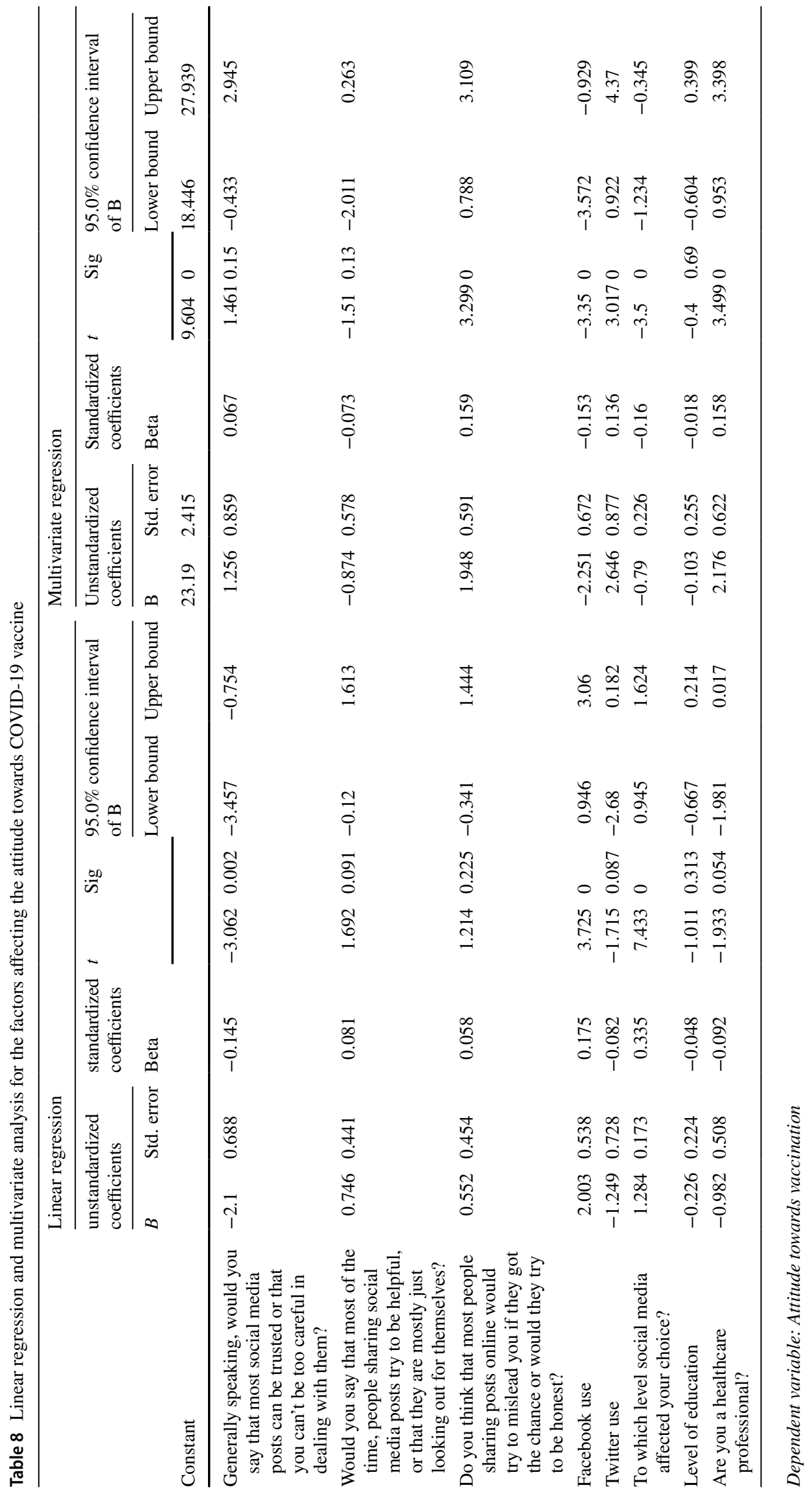


for healthcare providers in increasing the engagement of medical students, who are usually the most enthusiastic about spreading awareness and sharing scientific information, improving the interface with the public and improving networks around specific topics [30-32]. In this sense, Twitter is now the most popular medium among healthcare professionals [33], making the information available on this platform more valid and credible than on other platforms. Having a limited amount of characters for each tweet can be a significant disadvantage for those attempting to persuade people not to receive the vaccine [34]. It is worth noting that Twitter is the most user-friendly platform for viewers to actively participate, since it allows them to contact and follow doctors in the simplest way imaginable [35]. So, based on what was previously stated, and the fact that the majority of university students spend the majority of their time on Twitter [36], it is reasonable to consider Twitter to be a major contributor to the vaccination movement, aiding in better behaviour and attitude ( $p=0.002$ and $p=0.01$, respectively).

In terms of mental health, we discovered differences in psychological wellbeing, with Twitter users being more likely to indicate mental health concerns and Facebook users having higher overall scores. This finding contradicted a study conducted in the USA, which found that social media use was not predictive of poor mental health functioning [37]. With an increase in screen time, time spent with family has decreased, as have face-to-face interpersonal interactions, which is a primary driver of mental health deterioration [38].

Concerning the relation between mental health and attitude and behaviour towards COVID-19 vaccine, they were negatively correlated. Better mental health in Facebook users was associated with worse attitude and behaviour, while worse mental health in Twitter users was associated with better attitude and behaviour. This was common in several studies showing that psychiatric disorders were positively affecting the decision of vaccination $[39,40]$. This finding was unexpected in all studies.

There are several limitations to this study. To begin, our data reflects a snapshot in time, captured shortly after vaccines arrived in Lebanon. This would not have allowed social media campaigns to reach the entire population. Second, we did not analyse how the later emergence of several types of vaccines from different pharmaceutical companies, with potential risks and side effects, would influence people's attitude and decision to get vaccinated.

Third, despite targeting the source of information (platform) and tying it to attitude, this study does not measure knowledge, so we cannot create an opinion about which platform would be the best source of knowledge regarding COVID-19 vaccines and how it is displayed.
Fourth, just a few details about time spent on each social media platform were examined, making it impossible to build a quantitative relationship with the factors studied.

Fifth, no specificity regarding the type of vaccine was used in this questionnaire, which may have influenced participant selection.

Finally, this study only included students from one specific university, limiting our capacity to generalize findings on the general population and limiting our knowledge of less-educated people. These limitations, however, do not lessen the significance and validity of our work, as well as the need to expand its findings with additional research.

\section{Conclusion}

The use of COVID-19 vaccines is regarded as the most powerful intervention available so far to combat this pandemic. Nonetheless, various obstacles stand in the way of vaccinating a large percentage of the population, the most serious of which is a negative attitude towards vaccination. According to reports, social media has a significant part in shaping people's decision and changing their point of view. Our data demonstrated a high frequency of psychological well-being among Lebanese University students, which was correlated to frequent social media exposure during the COVID-19 pandemic. These findings suggested that students are more aware of misinformation and had lower rates of despair and anxiety than the general population. Furthermore, Facebook use was associated with worse attitude and behaviour towards vaccination, but a better mental health. Twitter had the inverse effect. This study emphasizes the need of using social media correctly in health-related topics, pushing governments and platforms towards making decisions about false and invalidated posts.

Data availability Data are available upon request from corresponding author.

\section{Declarations}

Conflict of interest The authors declare no competing interests.

\section{References}

1. Helmy YA, Fawzy M, Elaswad A et al (2020) The COVID-19 pandemic: a comprehensive review of taxonomy, genetics, epidemiology, diagnosis, treatment, and control. J Clin Med 9:E1225. https://doi.org/10.3390/jcm9041225

2. Rothe C, Schunk M, Sothmann P et al (2020) Transmission of 2019-nCoV infection from an asymptomatic contact in 
Germany. N Engl J Med 382:970-971. https://doi.org/10.1056/ NEJMc2001468

3. Huang C, Wang Y, Li X et al (2020) Clinical features of patients infected with 2019 novel coronavirus in Wuhan, China. Lancet 395:497-506. https://doi.org/10.1016/S0140-6736(20)30183-5

4. Gottlieb M, Dyer S (2020) Information and disinformation: social media in the COVID-19 crisis. Acad Emerg Med 27:640 641. https://doi.org/10.1111/acem.14036

5. Social media Definition \& Meaning - Merriam-Webster. https:// www.merriam-webster.com/dictionary/social\% 20 media. Accessed 19 Dec 2021

6. Ahmad AR, Murad HR (2020) The impact of social media on panic during the COVID-19 pandemic in Iraqi Kurdistan: online questionnaire study. J Med Internet Res 22:e19556. https://doi. org/10.2196/19556

7. Venegas-Vera AV, Colbert GB, Lerma EV (2020) Positive and negative impact of social media in the COVID-19 era. Rev Cardiovasc Med 21:561-564. https://doi.org/10.31083/j.rcm.2020. 04.195

8. Wang C, Pan R, Wan X et al (2020) Immediate psychological responses and associated factors during the initial stage of the 2019 coronavirus disease (COVID-19) epidemic among the general population in China. Int J Environ Res Public Health 17:E1729. https://doi.org/10.3390/ijerph17051729

9. Shu K, Sliva A, Wang S et al (2017) Fake news detection on social media: a data mining perspective. SIGKDD Explor Newsl 19:22-36. https://doi.org/10.1145/3137597.3137600

10. Tasnim S, Hossain MM, Mazumder H (2020) Impact of rumors and misinformation on COVID-19 in social media. J Prev Med Public Health 53:171-174. https://doi.org/10.3961/jpmph.20. 094

11. Mosolov SN (2020) Problems of mental health in the situation of COVID-19 pandemic. Zh Nevrol Psikhiatr Im S S Korsakova 120:7-15. https://doi.org/10.17116/jnevro20201200517

12. Muric G, Wu Y, Ferrara E (2021) COVID-19 vaccine hesitancy on social media: building a public Twitter data set of antivaccine content, vaccine misinformation, and conspiracies. JMIR Public Health Surveill 7:e30642. https://doi.org/10.2196/30642

13. González-Padilla DA, Tortolero-Blanco L (2020) Social media influence in the COVID-19 pandemic. Int Braz J Urol 46:120 124. https://doi.org/10.1590/S1677-5538.IBJU.2020.S121

14. Safieddine F, Kadry S, Masri W (2019) Misinformation on social media: the development of user behavior survey

15. del Sánchez-López M, P, Dresch V, (2008) The 12-Item General Health Questionnaire (GHQ-12): reliability, external validity and factor structure in the Spanish population. Psicothema 20:839-843

16. Montazeri A, Harirchi AM, Shariati M et al (2003) The 12-item General Health Questionnaire (GHQ-12): translation and validation study of the Iranian version. Health Qual Life Outcomes 1:66. https://doi.org/10.1186/1477-7525-1-66

17. Mannan D, Farhana K (2020) Knowledge, attitude and acceptance of a COVID-19 vaccine: a global cross-sectional study. 6:1-23. https://doi.org/10.2139/ssrn.3763373

18. Lebanese University. https://www.ul.edu.lb/lu/numbers.aspx. Accessed 7 Nov 2021

19. Qattan AMN, Alshareef N, Alsharqi O et al (2021) Acceptability of a COVID-19 vaccine among healthcare workers in the Kingdom of Saudi Arabia. Front Med (Lausanne) 8:644300. https://doi.org/10.3389/fmed.2021.644300

20. Kabamba Nzaji M, Kabamba Ngombe L, Ngoie Mwamba G et al (2020) Acceptability of vaccination against COVID-19 among healthcare workers in the Democratic Republic of the Congo. Pragmat Obs Res 11:103-109. https://doi.org/10.2147/ POR.S271096
21. Di Martino G, Di Giovanni P, Di Girolamo A et al (2020) Knowledge and attitude towards vaccination among healthcare workers: a multicenter cross-sectional study in a Southern Italian Region. Vaccines (Basel) 8:E248. https://doi.org/10.3390/ vaccines 8020248

22. Rapisarda V, Vella F, Ledda C et al (2021) What prompts doctors to recommend COVID-19 vaccines: is it a question of positive emotion? Vaccines (Basel) 9:578. https://doi.org/10.3390/ vaccines 9060578

23. Massey PM (2018) What drives health professionals to Tweet about \#HPVvaccine? Identifying strategies for effective communication. Prev Chronic Dis 15.https://doi.org/10.5888/pcd15. 170320

24. Kalichman SC, Eaton LA, Earnshaw VA, Brousseau N (2021) Faster than warp speed: early attention to COVD-19 by antivaccine groups on Facebook. J Public Health (Oxf) fdab093. https://doi.org/10.1093/pubmed/fdab093

25. Kim H, Han JY, Seo Y (2020) Effects of Facebook comments on attitude toward vaccines: the roles of perceived distributions of public opinion and perceived vaccine efficacy. J Health Commun 25:159-169. https://doi.org/10.1080/10810730.2020. 1723039

26. Orr D, Baram-Tsabari A, Landsman K (2016) Social media as a platform for health-related public debates and discussions: the Polio vaccine on Facebook. Isr J Health Policy Res 5:34. https:// doi.org/10.1186/s13584-016-0093-4

27. Campbell L, Evans Y, Pumper M, Moreno MA (2016) Social media use by physicians: a qualitative study of the new frontier of medicine. BMC Med Inform Decis Mak 16:91. https://doi. org/10.1186/s12911-016-0327-y

28. Osman A, Wardle A, Caesar R (2012) Online professionalism and Facebook-falling through the generation gap. Med Teach 34:e549-556. https://doi.org/10.3109/0142159X.2012.668624

29. Connelly Y, Ziv A, Goren U et al (2016) Using the social structure of markets as a framework for analyzing vaccination debates: the case of emergency polio vaccination. Hum Vaccin Immunother 12:1930-1935. https://doi.org/10.1080/21645515. 2016.1147637

30. Forgie SE, Duff JP, Ross S (2013) Twelve tips for using Twitter as a learning tool in medical education. Med Teach 35:8-14. https://doi.org/10.3109/0142159X.2012.746448

31. Cahn PS, Benjamin EJ, Shanahan CW (2013) "Uncrunching" time: medical schools' use of social media for faculty development. Med Educ Online 18:20995. https://doi.org/10.3402/meo. v18i0.20995

32. Hawkins CM, Duszak R, Rawson JV (2014) Social media in radiology: early trends in Twitter microblogging at radiology's largest international meeting. J Am Coll Radiol 11:387-390. https://doi.org/10.1016/j.jacr.2013.07.015

33. Raghupathi W, Raghupathi V (2014) Big data analytics in healthcare: promise and potential. Health Inf Sci Syst 2:3. https://doi.org/10.1186/2047-2501-2-3

34. Choo EK, Ranney ML, Chan TM et al (2015) Twitter as a tool for communication and knowledge exchange in academic medicine: a guide for skeptics and novices. Med Teach 37:411-416. https://doi.org/10.3109/0142159X.2014.993371

35. Pershad Y, Hangge PT, Albadawi H, Oklu R (2018) Social medicine: Twitter in healthcare. J Clin Med 7:121. https://doi. org/10.3390/jcm7060121

36. Bicen H, Cavus N (2012) Twitter usage habits of undergraduate students. Procedia Soc Behav Sci 46:335-339. https://doi.org/ 10.1016/j.sbspro.2012.05.117

37. Berryman C, Ferguson CJ, Negy C (2018) Social media use and mental health among young adults. Psychiatr Q 89:307-314. https://doi.org/10.1007/s11126-017-9535-6 
38. Pantic I (2014) Online social networking and mental health. Cyberpsychol Behav Soc Netw 17:652-657. https://doi.org/10. 1089/cyber.2014.0070

39. Ren X, Shen F, Gui Y et al (2021) The attitudes of psychiatric patients towards COVID-19 vaccination in China: a crosssectional study. BMC Psychiatry 21:475. https://doi.org/10. 1186/s12888-021-03484-9

40. Danenberg R, Shemesh S, Tzur Bitan D et al (2021) Attitudes of patients with severe mental illness towards COVID-19 vaccinations: a preliminary report from a public psychiatric hospital. J Psychiatr Res 143:16-20. https://doi.org/10.1016/j. jpsychires.2021.08.020

Publisher's Note Springer Nature remains neutral with regard to jurisdictional claims in published maps and institutional affiliations. 